\title{
Adaptation of the "Attitudes Toward Physical Activity Scale" for Higher Education Students in Turkey
}

\author{
Sirrı Cem Dinc ${ }^{1}$, Fatma Sacli Uzunoz ${ }^{1}$, Magdalena Mo Ching Mok $^{2,3} \&$ Ming-Kai Chin ${ }^{4,5}$ \\ ${ }^{1}$ Nevşehir Hacı Bektaş Veli University, School of Sport Sciences and Technology, Nevşehir, Turkey \\ ${ }^{2}$ The Education University of Hong Kong, Department of Psychology and Assessment Research Centre, Hong \\ Kong, China \\ ${ }^{3}$ Graduate Institute of Educational Information and Measurement, National Taichung University of Education, \\ Taichung, Taiwan \\ ${ }^{4}$ The Foundation for Global Community Health (GCH), Las Vegas, Nevada, USA \\ ${ }^{5}$ HOPSports, Inc., Las Vegas, Nevada, USA \\ Correspondence: Fatma SAÇLI UZUNÖZ, School of Sport Sciences and Technology, Nevsehir Haci Bektas \\ Veli University, 2000 Evler Mah. Damat İbrahim Pasa Kampüsü H Blok. Turkey. E-mail: \\ fatmasacli@gmail.com
}

$\begin{array}{ll}\text { Received: March 1, } 2019 & \text { Accepted: March 25, } 2019 \quad \text { Online Published: March 29, } 2019 \\ \text { doi:10.5539/jel.v8n3p95 } & \text { URL: https://doi.org/10.5539/jel.v8n3p95 }\end{array}$

\begin{abstract}
The purpose of this study was to adapt the "Attitudes toward Physical Activity Scale" (APAS) for Turkish higher education students. Study was conducted during 2018-2019 autumn semester at a public university in the central Anatolia region of Turkey. The APAS was applied to 1021 voluntary university students from eleven different faculties and departments of the university. Descriptive statistics, exploratory and confirmatory factor analyses, internal consistency coefficients were used in statistical analysis. Exploratory factor analysis revealed a six factor solution explaining $60.2 \%$ of the variance. Then, confirmatory factor analysis on the 38 items showed good fit to the 6-dimension model according to the goodness-of-fit criteria. The psychometric data of the scale showed that the Turkish version of the scale for higher education students reached the required levels. As a result, the "Attitudes toward Physical Activity Scale" can be used in reliable and valid way at higher education students in Turkey at national or cross-cultural studies in examining physical activity attitudes.
\end{abstract}

Keywords: physical activity, attitudes, measurement, higher education

\section{Introduction}

As in the whole world, in Turkey, inactivity is increasingly prevalent in every period from childhood to old age. According to the press release of Turkish Statistical Institute, the results of Turkey Health Interview Survey showed that the percentage of obese individuals aged 15 and over was $19.9 \%$ in Turkey in 2014, it decreased to $19.6 \%$ in 2016. When the most recent data of the European Union (EU) was examined in 2014, this rate was $15.4 \%$ in the EU. Among the selected EU countries, ranks of Malta was first with $25.2 \%$, Latvia was second with $20.8 \%$, followed by Hungary and Turkey with $20.6 \%$ and $19.9 \%$. This shows that one out of five people struggles with obesity in Turkey (TurkStat, 2017). According to the results of Poobalan et al. (2012), 18-25 year olds have low levels of physical activity and consequently are vulnerable to weight gain. Physical activity levels also decreased with age and the time spent on computers/game consoles, whether for work/study or pleasure, increased gradually within this age group. Results also revealed that many did not commence any new sport after moving to university in spite of being active at school.

Regarding this problem, technology is being integrated into the learning environments at universities just like the schools as a necessity of being in the age of new millennium to promote physical activity and movement culture. Because studies showed that implementing short physical activity breaks in classroom can be a way to improve student physical activity behavior in schools (Carlson et al., 2015; Käll, Nilsson, \& Lindén, 2014; Turner \& Chaloupka, 2017). As Poobalan et al. (2012) mentioned, 18-25 year olds preferred doing physical activity for enjoyment rather than meeting social expectations. Therefore, that might be a starting point to improve positive attitudes towards physical activity and promote healthy living in this age group as well. 
Recently, On-Line-Streaming (OLS) Brain Breaks (BB) videos in classrooms all around the world is being served to make children more active and better learners (Lithuania [Emeljanovas et al., 2018], Poland [Glapa et al., 2018], Malaysia [Kuan et al., 2019], Macedonia [Popeska et al., 2018], Turkey [Sacli Uzunoz et al., 2017]). In the framework of collaborative action research, projects had been conducted using this technology supported programs at national and global levels since 2014 in Turkey as well. Positive results obtained from school kids and related studies in literature mentioned before encouraged the initiation of this applications into the teaching process at higher education. As the first step of a large project, it was necessary to have a reliable and a valid scale measurements that could be used at higher education level as well.

Attitudes toward Physical Activity Scale (APAS) has been using at many countries (Emeljanovas et al., 2018; Glapa et al., 2018; Kuan et al., 2019; Popeska et al., 2018; Sacli Uzunoz et al.) to measure school childrens' attitudes toward physical activity, particularly on personally estimate level of physical fitness, self-efficacy, goal orientation, interest for physical activity, self-awareness for the importance and benefits from physical activity and its contribution in learning for health and holistic development. Mok et al. (2015) revealed psychometric properties of the scale after a rasch analysis based on data from five countries (Lithuania, Poland, Serbia, Singapore and Zimbabwe) at global level. Rasch analysis showed empirical evidence in support of measurement validity and reliability of the APAS for school childrens in classroom settings at various geographical locations globally. Therefore, the purpose of this study was to examine the realibility and validity of the "Attitudes toward Physical Activity Scale" (Mok et al., 2015) for measurements of Turkish higher education students.

\section{Method}

\subsection{Participants}

In the current study, APAS was applied to $1021(40 \%$ males $n=411,60 \%$ females $n=610)$ voluntary university students at each class level (Mage $=20.8$ years, $\mathrm{SD}=2.24$ years) from twelve different faculties and departments during 2018-2019 autumn semester at a public university in the central Anatolia region of Turkey. The sampling distribution across faculties and departments is presented below in Table 1.

Table 1. Distribution of participants across faculties and departments

\begin{tabular}{lll}
\hline Faculties and Departments & $n$ & $\%$ \\
\hline Nursing & 194 & 19.0 \\
Economics \& Administrative & 40 & 3.9 \\
Elementary Education & 36 & 3.5 \\
Physical Education & 186 & 18.2 \\
Foreign Languages & 59 & 5.8 \\
Science and Literature & 116 & 11.4 \\
Theology & 107 & 10.5 \\
Sport Sciences \& Technology & 70 & 6.9 \\
Turkish and Social Sciences Education & 86 & 8.4 \\
Tourism & 53 & 5.2 \\
Engineering & 24 & 2.4 \\
Vocational Training & 50 & 4.9 \\
Total & 1021 & 100 \\
\hline
\end{tabular}

The student number with the most weight in sample were nursing, physical education, science and literature, theology, Turkish and social sciences education, respectively. According to class level, the distribution was similar for the freshman, sophomore and junior however, it was the least for senior as it was seen below in Table 2.

Table 2. Distribution of participants across class level

\begin{tabular}{lll}
\hline Class Level & $n$ & $\%$ \\
\hline Freshman & 340 & 33.3 \\
Sophomore & 251 & 24.6 \\
Junior & 339 & 33.2 \\
Senior & 91 & 8.9 \\
Total & 1021 & 100 \\
\hline
\end{tabular}




\subsection{Instrument and Procedure}

The "Attitudes toward Physical Activity Scale" (APAS) (Mok et al., 2015) was used in this study which was designed in English for larger global projects. A total of 58-item APAS is 4-point Likert-type scale ranging from Strongly Disagree, Disagree, Agree, and Strongly Agree. There are seven subscales: Benefits (10 items): Students' perceived benefits of physical activity. An example item is, "Being physically active helps to give me more willpower." Importance (5 items): Students' perceived importance of physical activity. An example item is, "It is important to be physically active for my health." Learning (11 items): Students' learning from the Brain Break ${ }^{\circledR}$ videos. An example item is, "I learned about music through video exercise." Self-efficacy (4 items): Students' self-efficacy in selecting video exercises for themselves. An example item is, "I know how to do physical activity if there is a video exercise to follow." Fun (14 items): Students' interest in doing physical activity. An example item is, "I think physical activity is fun." Fitness (8 items): Students' confidence in their own fitness. An example item is, "I am confident with my balance." Personal Best (5 items): Students' personal best goal orientation when engaging in physical activity. An example item is, "I keep striving for breakthroughs in physical activity." After translation (with back-translation) process of APAS, reliability and validity of the data obtained from school childrens had already been completed by Sacli Uzunoz et al. (2017) in Turkey. Therefore, the translation process was not required again, so validity and reliability analyses were applied directly on the data obtained from university students in the current study.

\subsection{Analysis}

Once the participants' responses were collected, the data were analyzed using IBM SPSS for Windows (Version 20). In order to examine the reliability of the instrument, the internal consistency (Cronbach's alpha) method was used. Spearman-Brown and the Guttman Split-Half correlation values were also calculated. Lastly, it was decided to undertake exploratory and confirmatory factor analyses in order to evaluate the construct validity of the instrument. Descriptive statistics were also used to show distribution of the participants.

\section{Results}

To establish an initial factor structure for the Turkish version of the APAS for higher education students, an exploratory factor analysis was conducted using a principal components method. Initially, 58 items of the original questionnaire (Mok et al., 2015) were submitted for analysis. Factor criteria included: (1) items should correlate with the factor with loading $>.50$; (2) items should not cross-load on the other factors with factor loading > .30; and (3) each factor should be composed of not less than three items. Following a priori criteria, twenty items (a1, a6, a9, b1, b2, b3, b4, b5, c4, c6, c7, d3, e4, e1, e2, e5, e8, e12, e13, e15) were deleted from further analysis for failure to match in these criteria construct validity (Field, 2009; Huang, 2005; Liu,2003; Tsai \& Chai, 2005). The items extracted from each sub-scale were given below (see Table 3).

Table 3. Extracted items from the APAS for higher education students

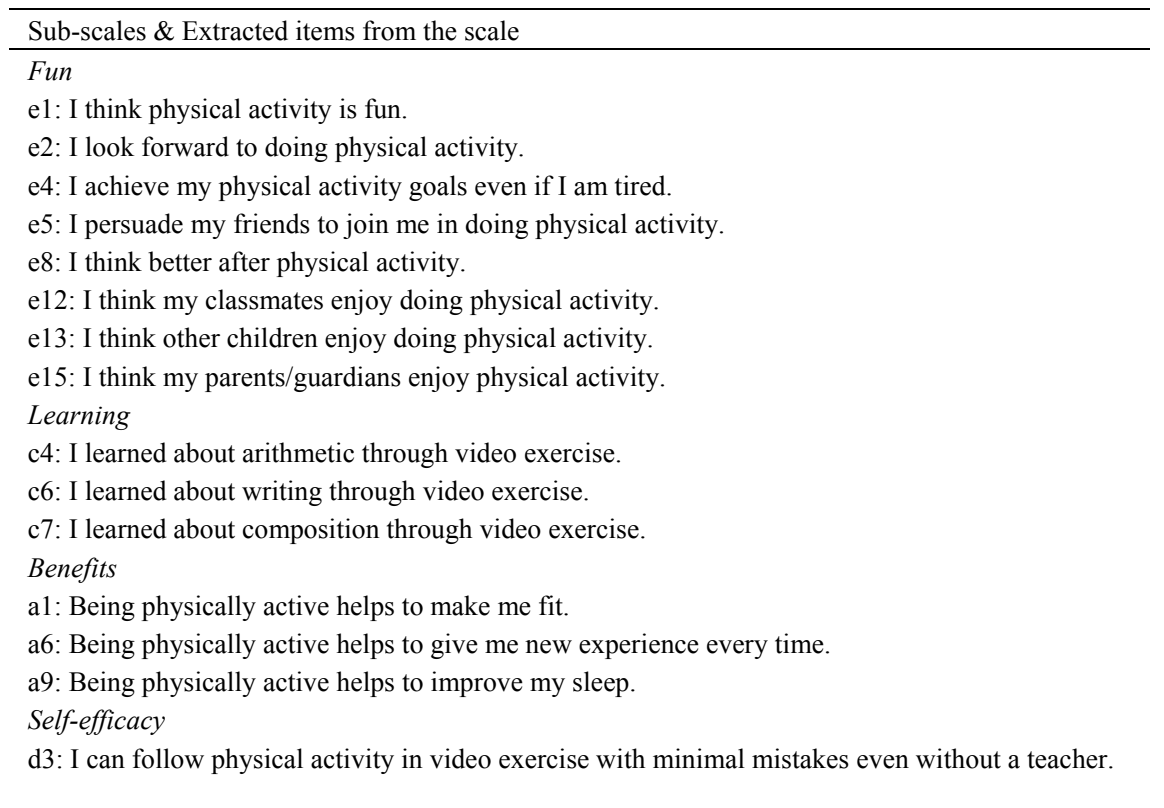


The procedure was then repeated. The exploratory factor analysis revealed a six factor solution with eigenvalues from 16.27 to 1.37 explaining $60.2 \%$ of the variance with 38 items (see Table 4 ).

Table 4. Factor structure of the APAS from exploratory factor analysis $(\mathrm{n}=1021)$

\begin{tabular}{|c|c|c|c|c|c|c|}
\hline \multirow[t]{2}{*}{ Sub-scales \& Items } & \multicolumn{6}{|c|}{ Factors } \\
\hline & 1 & 2 & 3 & 4 & 5 & 6 \\
\hline \multicolumn{7}{|l|}{ Fun } \\
\hline e3 I enjoy doing physical activity with my classmates & .52 & & & & & \\
\hline e6 I feel better after physical activity & .52 & & & & & \\
\hline e7 I feel stronger after physical activity & .57 & & & & & \\
\hline e9 I think better after physical activity & .57 & & & & & \\
\hline e10 I improve on my school work after physical activity & .63 & & & & & \\
\hline e11 I think my good friends enjoy doing physical activity & .70 & & & & & \\
\hline e14 I think my teachers enjoy doing physical activity & .62 & & & & & \\
\hline \multicolumn{7}{|l|}{ Learning } \\
\hline c1 I learned about culture through video exercise & & .60 & & & & \\
\hline c2 I learned about music through video exercise & & .69 & & & & \\
\hline c3 I learned about art through video exercise & & .76 & & & & \\
\hline c5 I learned about language through video exercise & & .72 & & & & \\
\hline c8 I learned about healthy lifestyle from video exercise & & .56 & & & & \\
\hline c9 I learned about healthy diet from video exercise & & .58 & & & & \\
\hline c10 I learned about hygiene from video exercise & & .67 & & & & \\
\hline c11 I learned about environmental protection from video exercise & & .70 & & & & \\
\hline \multicolumn{7}{|l|}{ Benefits } \\
\hline a2 Being physically active helps to relax me & & & .80 & & & \\
\hline a3 Being physically active helps to improve my thinking & & & .83 & & & \\
\hline a4 Being physically active helps to improve my analytic skills & & & .80 & & & \\
\hline a5 Being physically active helps to enhance my self-concept & & & .73 & & & \\
\hline a7 Being physically active helps to give me more willpower & & & .68 & & & \\
\hline a8 Being physically active helps to give me good health & & & .66 & & & \\
\hline a10 Being physically active helps to improve my school work & & & .59 & & & \\
\hline \multicolumn{7}{|l|}{ Fitness } \\
\hline f1 I am confident with my strength & & & & .79 & & \\
\hline f2 I am confident with my endurance & & & & .81 & & \\
\hline f3 I am confident with my balance & & & & .83 & & \\
\hline f4 I am confident with my agility & & & & .87 & & \\
\hline f5 I am confident with my flexibility & & & & .80 & & \\
\hline f6 I am confident with my rhythm & & & & .78 & & \\
\hline f7 I am confident with my hand-eye coordination & & & & .72 & & \\
\hline f8 I am confident in doing physical activity elegantly & & & & .58 & & \\
\hline \multicolumn{7}{|l|}{ Self-efficacy } \\
\hline d1 I know how to choose physical activity in video exercise that suits me & & & & & .68 & \\
\hline d2 I know how to do physical activity if there is a video exercise to follow & & & & & .66 & \\
\hline $\mathrm{d} 4 \mathrm{I}$ know which is my favorite physical activity in video exercise & & & & & .61 & \\
\hline \multicolumn{7}{|l|}{ Personal best } \\
\hline g1 I try my best to engage in physical activity & & & & & & .78 \\
\hline g2 My target is to go beyond what I have achieved in physical activity & & & & & & .85 \\
\hline g3I keep striving for breakthroughs in physical activity & & & & & & .79 \\
\hline g4 I just do my personal best in physical activity & & & & & & .79 \\
\hline g5 I seek to explore my best potential in physical activity & & & & & & .82 \\
\hline Eigenvalues & 16.27 & 3.69 & 3.37 & 2.42 & 2.17 & 1.37 \\
\hline Percentage of explained variance & 35.5 & 7.7 & 5.4 & 4.9 & 3.5 & 3.2 \\
\hline Percentage of total explained variance & 35.5 & 43.2 & 48.6 & 53.5 & 57.0 & 60.2 \\
\hline Internal consistency (Cronbach's alpha) & .84 & .88 & .88 & .91 & .82 & .90 \\
\hline
\end{tabular}


Internal consistency (Cronbach's alpha) of each factor ranged from .82 to .91 , and it was .94 for the whole scale. Two-Half (Split-Half) test reliability was also calculated the data obtained from 1021 participants by using the Spearman-Brown formula $[\mathrm{r}$ Test $=(2 \mathrm{r} / 1+\mathrm{r})$, where $\mathrm{r}$ stands for correlation]. According to the results of the Spearman-Brown correlation value was .88; The Guttman Split-Half correlation value was .88. The obtained internal consistency scores were higher than the original version of the APAS which ranged from .63 to .84 as reported by Mok et al. (2015).

When confirmatory factor analysis was conducted on the 38 items (using AMOS software) the results showed good fit to the 6-dimension model according to the goodness-of-fit criteria, with CFI equal to .95, with TLI equal to .95 , RMSEA equal to .04 (90\% Confidence Interval), and all standardized path coefficients were in the range of .54 and .86 , and statistically significant $\left(\mathrm{x}^{2} / \mathrm{sd}\right.$ values $>2.70$, where $\mathrm{x}$ stands for a path coefficient, and sd is the standard deviation). Details were given at figure 1 below.

Given that the APAS scale was designed according to a conceptual framework (Mok et al., 2015) and that previous studies have found evidence in support of the factor structure of the APAS scale as designed, a confirmatory factor analysis undertaken in this study also confirmed the factor structure of the scale for this sample of Turkey university students.

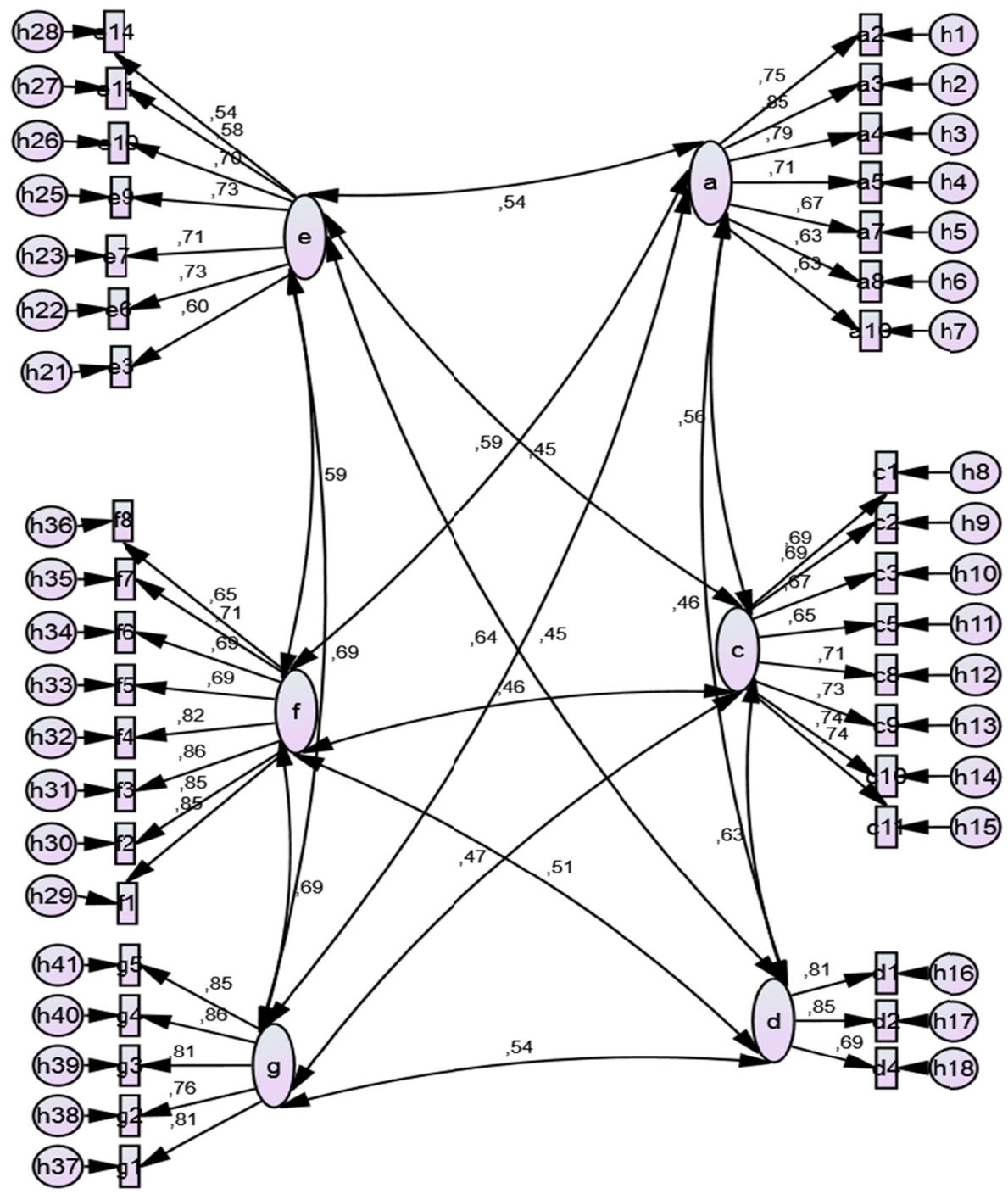

Figure 1. Results of confirmatory factor analysis ( $a=$ Benefits, $c=$ Learning, $d=$ Self-efficacy, $e=$ Fun, $f=$ Fitness, $\mathrm{g}=$ Personal Best subscales) 
As the results of confirmatory factor analysis were examined in detail, model goodness-of-fit was considered adequate when fit statistics Comparative Fit Index (CFI) was $\geq .95$, Tucker-Lewis Index (TLI) was $\geq .95$, Root Mean Square Error of Approximation (RMSEA) was $<.05$, and standardized path coefficients were $\geq .50$ and statistically significant $\left(\mathrm{x}^{2} / \mathrm{sd}\right.$ values $\left.>2.70\right)$. These results show that the APAS sub-scales can be considered reliable and valid for use with Turkey university students on the basis of citeria recommended in the literature (Kline, 2016).

\section{Discussion}

The structure of the scale were examined by comparing with the original APAS scale (Mok et al., 2015) and Turkish version for the school children (Sacli Uzunoz et al., 2017), it would not be wrong to say that there was not a serious change in general. The most remarkable point was the "importance" sub-scale was completely out of the scale, even although it consisted of 5 items in original APAS scale and remained in place with 4 items in the Turkish version for the school children. Other substantial change was the sub-scales of "learning" and "self-efficacy" merged into 15 items in Turkish version for school children appeared as separate sub-scales in this study as in the original scale. The sub-dimension of "learning", which was 11 items on the original scale, was reduced to 8 items, and the sub-scale of "self-efficacy", which was 4 items on the original scale, was reduced to 3 items in the current study. The "fun" sub-scale, which consisted of 14 items on the original scale, was already reduced to 11 items in the Turkish version for school children and now consisted of 7 items for higher education students. The "personel best" sub-scale, which consisted of 5 items on the original scale, was already reduced to 4 items in the Turkish version for school children and now again consisted of 5 items as in the original scale. The "benefits" sub-scale, which consisted of 10 items on the original scale, was already reduced to 9 items in the Turkish version for school children and now consisted of 7 items in the current study. There was no any change in the item number of "fitness" sub-scale, both in the Turkish version for school children and Turkish version for higher education students it remained 8 items as in the original scale.

When examining the psychometric data of the scale, it can be concluded that the Turkish version of the scale for higher education students reached the required levels.

Exploratory and confirmatory factor analyses as well as internal reliability analyses demonstrated satisfactory results regarding the psychometric properties of the APAS for higher education students in Turkey. In this way, the implementation of Brain Breaks ${ }^{\circledR}$ can be examined at higher education level and its effect on students' attitudes being gauged using APAS. These studies can be spread to the whole country, then can also be conducted at cross-cultural level to promote physical activity participation in higher education level.

Taking into account the fact that the only attitudes to predict the physical activity participation is not enough, it can be said that there is still a lot of work to be done in order to obtain sufficient evidence regarding the impact of attitudes as a determinant of physical activity participation.

\section{Acknowledgments}

Any grants or other financial support was not received for our study. I assert that written informed consent was taken from participants for reporting the results. The manuscript is original work of both authors and each made a significant contribution on this study. None of the writers is the person's routinely involved in the review and acceptance of manuscripts peer reviewers and editors associate editors, and consulting editors of the journal. I confirm that this manuscript has not been published elsewhere nor is it currently under consideration for publication in any other journal. I affirmed that both authors have read and approved the final version of the manuscript. Some part of this study was presented as an oral presentation at 5th International Conference of Physical Education and Sport Sciences which was held in Nevşehir, Turkey, 4-6 Dec 2018. We wish to thank all participants and the university where this research was undertaken.

\section{References}

Carlson, J. A., Engelberg, J. K., Cain, K. L., Conway, T. L., Mignano, A. M., Bonilla, E. A., Geremia, C., \& Sallis, J. F. (2015). Implementing classroom physical activity breaks: Associations with student physical activity and classroom behavior. Preventive Medicine, 81, 67-72. https://doi.org/10.1016/j.ypmed.2015.08.006

Emeljanovas, A., Mieziene, B., Mok, M. M. C., Chin, M. K., Cesnaitiene, V. J., Fatkulina, N., Trinkuniene, L., López Sánchez, G. F., \& Díaz Suárez, A. (2018). The effect of an interactive program during school breaks on attitudes toward physical activity in primary school children. Anales De Psicología/Annals of Psychology, 34(3), 580-586. https://doi.org/10.6018/analesps.34.3.326801

Field, A. (2009). Discovering Statistic: Using SPSS. Sage. Los Angeles. 
Glapa, A., Grzesiak, J., Laudanska-Krzeminska, I., Chin, M. K., Edginton, C. R., Mok, M. M. C., \& Bronikowski, M. (2018). The impact of brain breaks classroom-based physical activities on attitudes toward physical activity in Polish school children in third to fifth grade. International Journal of Environmental Research and Public Health, 15(2), 368. https://doi.org/10.3390/ijerph15020368

Huang, H. M. (2005). Web performance scale. Information and Management, 42, 841-852. https://doi.org/10.1016/j.im.2004.06.003

Käll, L. B., Nilsson, M., \& Lindén, T. (2014). The impact of a physical activity intervention program on academic achievement in a Swedish elementary school setting. Journal of School Health, 84, 473-480. https://doi.org/10.1111/josh.12179

Kline, R. B. (2016). Principles and practice of structural equation modeling (4th ed.). New York, NY: The Guilford Press.

Kuan, G., Rizal, H., Hajar, M. S., Chin, M. K., \& Mok, M. M. C. (2019). Bright Sports, physical activity investments that work: Implementing Brain Breaks ${ }^{\circledR}$ in Malaysian primary schools. British Journal of Sports Medicine, 0, 1-2. https://doi.org/10.1136/bjsports-2018-100146

Liu, Y. (2003). Developing a scale to measure the interactivity of websites, Journal of Advertising Research, June, 207-217. https://doi.org/10.2501/JAR-43-2-207-216

Mok, M. M. C., Chin, M. K., Chen, S., Emeljanovas, A., Mieziene, B., Bronikowski, M., \& Phua, K. W. (2015). Psychometric properties of the attitudes toward physical activity scale: A Rasch analysis based on data from five locations. Journal of Applied Measurement, 16(4), 379-400. PMid: 26771567.

Poobalan, S. A., Aucott, S. L., Clarke, A., \& Smith, W. C. (2012). Physical activity attitudes, intentions and behaviour among 18-25 year olds: A mixed method study. BMC Public Health, 12, 640. https://doi.org/10.1186/1471-2458-12-640

Popeska, B., Jovanova-Mitkovska, S., Chin, M. K., Edginton, C. R., Mok, M. M. C., \& Gontarev, S. (2018). Implementation of Brain Breaks ${ }^{\circledR}$ in the classroom and effects on attitudes toward physical activity in a Macedonian school setting. International Journal of Environmental Research and Public Health, 15(6), 1127. https://doi.org/10.3390/ijerph15061127

Sacli Uzunoz, F., Chin, M. K., Mok, M. M. C., Edginton, C. R., \& Podnar, H. (2017). The effects of technology supported brain breaks on physical activity in school children. Passionately Inclusive: Towards Participation and Friendship in Sport: Festschrift für Gudrun Doll-Tepper (pp. 87-104). Waxmann.

Tsai, L. S., \& Chai, K. S. (2005). Developing and validating a nursing website evaluation questionnaire, Methodological Issues in Nursing Research, 49(4), 416-413. https://doi.org/10.1111/j.1365-2648.2004.03304.x

Turkish Statistical Institute (TurkStat). (2017). Retrieved $\quad$ October 12, 2018, from http://www.tuik.gov.tr/basinOdasi/haberler/2017_31_20170607.pdf

Turner, L., \& Chaloupka, F. J. (2017). Reach and implementation of physical activity breaks and active lessons in elementary school classrooms. Health Education \& Behavior, 44(3), 370-375. https://doi.org/10.1177/1090198116667714

\section{Copyrights}

Copyright for this article is retained by the author, with first publication rights granted to the journal.

This is an open-access article distributed under the terms and conditions of the Creative Commons Attribution license (http://creativecommons.org/licenses/by/4.0/). 